\title{
РАЗРЕШЕНИЕ И УПРАВЛЕНИЕ КОНФЛИКТАМИ В КУЛЬТУРАХ РОССИИ И КИТАЯ
}

\author{
Леонов Н.И., Главатских В.Г., Главатских М.М. (Удмуртскийй \\ государственный университет, Ижевск, Россия,) \\ nileonov@mail.ru,ni-hao@mail.ru,v.glavatskikh@inbox.ru

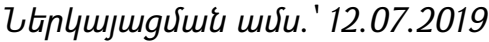

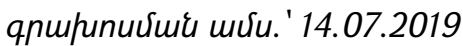 \\ цимшарпьрјшй дйппийши шर्रи. '13.09.2019
}

Нарастание напряженности в современном мире обязывает современную психологию находить пути к управлению конфрликтами таким образом, что сам конфликт является управляемым процессом, исход которого должен иметь конструктивный характер, ведущий к снятию противоречий и напряженности в обществе. В статье раскрывается специфика управления конфликтом и степень влияния третьих лиц в конфликте в культурах России и Китая. Определены роли третьих лиц в управлении конфрликтом В разных культурах. В статье культура рассматривается как система формирующая сознание личности, проявляющаяся в мифах и легендах народов.

Ключевые слова: Образ конфрликтной ситуачии, представления о конфрликте, способ разрешения конфрликтов.

Современные проблемы психологии управления касаются множества сфрер применения личности каждого человека и деятельности общества в целом. Конфрликты в обществе, охватившие все сферы деятельности современного человека вынуждают искать решения для разрешения конфрликтов и управления ими. Проблема исследования в области управления конфрликтами связана с тем, что отношение к конфрликту и способам его разрешения обусловлено спецификой мышления членов общества, представителей той или иной культуры. Установлено, что конфрликтное поведение - пространственно - временная организация активности субъекта, регуляция которой опосредована образом конфрликтной ситуации[5]. Сам же образ конфрликтной ситуации есть часть социальных представлений. Социальное представление - как система верований и знаний, присущих каждой культуре обладает организованной структурой; во-вторых, разделяется членами конкретной группы людей; в-третьих, является социальной по происхождению, т.е. формируется в процессах межличностной и массовой коммуникаций; в-четвертых, социально полезна, т.к. задает критерии для понимания, интерпретации и оценки социального окружения [7]. Таким образом, культура общества формирует социальные представления, определяет некий социальный формат человека, его социальное поведение, в том числе и в ситуации конфрликта. 
Под влиянием культуры общества формируются социальные ценности, нормы поведения и ролевые функции. «В связи с различием культур различных обществ формируются различные, зачастую непохожие нормы и ценности. Под влиянием собственной культуры формируется субъективное видение своего мира, образа жизни, манеры общения. Поведение человека в обществе определено рамками норм собственной культуры. При взаимодействии с другой культурой субъект начинает воспринимать ее сквозь призму своей культуры. Данный инструмент восприятия определяет как культура как линза»[4]. В ходе своей жизни каждая личность совершает множество социальных актов, примеряя на себе различные роли, проявление которых обусловлено как внутренним бессознательным, так и социокультурными слоями общества.

Психосоциальный мир человека в значительной мере обусловлен не только внутренними посылами бессознательного, но и воздействием на него культуры народов. Такой процесс взаимодействия лучшим образом описывается в нарративном ключе. Как определил Э. Гидденс: «Идентичность человека не может быть обнаружена ни в его поведении, ни, как бы важно это ни было, в реакциях других людей, но она зависит от способности поддерживать определенный нарратив" [6]. Опираясь на психосоциальные структуры личности, социальную обусловленность Д.П. Макадамс определяет связь социально жизни общества с культурой общества, чертами и характеристиками личности и его нарративной историей. История идеально подходит для того, чтобы понять, каким образом человек, деятель, наделенный сознанием и мотивированный своим намерением, воплощает свои убеждения и стремится к целям во времени и в социальном контексте [9]. Наративный подход в своей сути основывается на проблеме идентичности, он опирается на систему развития личности в социальной среде, обусловленной культурными, историческими и национальными составляющими, чем определят собой онтологический подход. Э. Эриксон, МакАдамс [6] определяют нарратив как жизненную историю, где индивид выстраивает целостную историю, и рассматривается как структура регулирующая сознание и развитие человека.

Нарратив имеет культурную заданность. Жизненные истории отражают ту культуру, в которой история создается и рассказывается. Истории живут в культуре. Они рождаются, растут, процветают, размножаются, благоденствуют и постепенно умирают согласно нормам, правилам и традициям, которые существуют в данном обществе, согласно тем критериям «жизни, достойной рассказывания», «истории, достойной рассказывания», которые существуют в данной культуре. Как обозначил это Дж. Розенвальд, «когда люди рассказывают истории жизни, они действуют в соответствии с моделями понимания, присущими конкретной культуре» [3] Сарбин Т. [8] констатирует, что нарратив - это есть метатеоретическая парадигма: «люди думают, воспринимают, воображают и совершают моральные выборы согласно 
нарративным структурам». У Д. Брунера нарратив выстраивается на утверждении «И хорошая история, и хорошо сорормулированные логические выражения являются естественными типами рассуждения, оба могут быть использованы для убеждения. Однако то, в чем они убеждают, имеет фундаментальные различия: логические аргументы убеждают в истинности, а истории - в их жизненном правдоподобии» [6]. Жизнь, её повествование - это создание и презентация собственного формирующегося в данной культуре образа. Для осмысления поступков, поведения, формирования характера людей необходимо обратится к традиционным сюжетам, характерным для его культуры человека, с помощью которых можно объединить цепочку разрозненных, и казалось не связанных между собой жизненных событий в единое целое. Эти сюжеты могут быть переданы в форме мифов, сказок, поэзии или в любой иной вербальной или невербальной форме.

Культура как система имеет в своем арсенале множество способов формирования сознания личности, одним из таких способов являются мифы и легенды народов. Неся в себе нарративно - дискурсивный посыл миф «предлагает» те или иные способы и методы для решения различных жизненных вопросов, в том числе и разрешение конфлликтов. В мифе уже прописаны методики для различных ситуаций, этот, что то наподобие «инструкции к применению» в быту человека. Принимая во внимание, что в различных культурах сформировалось множество таких «инструкций», они иногда одинаковые, а зачастую и различные методические подходы к однотипным ситуациям. Таким образом, было проведено исследование управления и разрешения конфликтных ситуаций в культурах России и Китая на материале мифов и сказок.

Управление конфрликтом - сознательная деятельность по отношению к нему, осуществляемая на всех этапах его возникновения, развития и завершения участниками конфрликта или третьей стороной [1]. В ходе исследования, с применением метода качественно - количественного контент анализа сказок и мифов России и Китая был выявлен параметр “Управление конфрликтом», как характерный признак в культуре при взаимодействии основных участников конфликта и влиянии на ход конфллика со стороны третьих лиц. По роли в конфрликте третьих лиц были определены следующие признаки:

- Провокация конфликта.

- Силовое решение конфликта.

- Устранение предмета конфликта.

- Лицо направляет на решение своих интересов.

- Справедливый арбитраж.

По результатам обработки данных методом качественно - количественного контент анализа мифов и сказок были выявлены следующие различия роли участия в конфрликтной ситуации третьих лиц. На достоверном уровне выявлены различия по наличию провокации участников конфрликта третьими лицами в сказках 
(социально - культурных традициях) Китая (СКТ Китая) и России (СКТ России) с применением $X^{2}$ Р. Пирсона $\left(X^{2}=3,8, p=0,049\right)$. На рисунке 1 видно, что третье лицо провоцирует в Китайских сказках участников к конфликтному взаимодействию чаще.

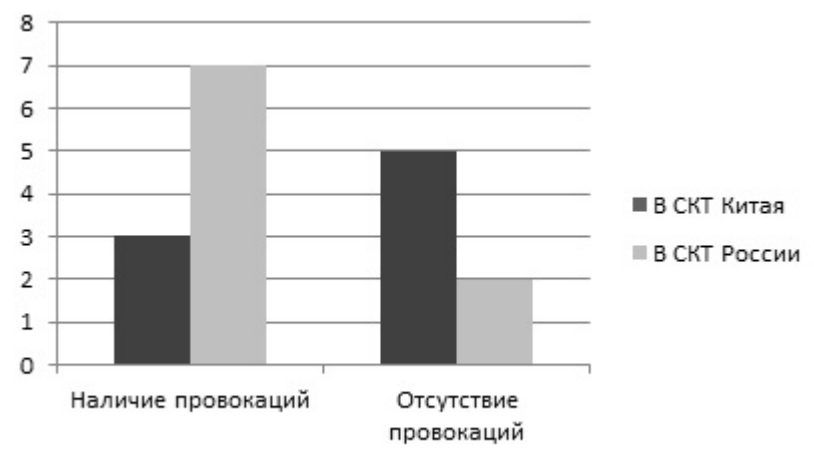

Рисунок 1. Наличие и отсутствие провокаций со стороны третьих лиц в конфрликтной ситуации в текстах Китая и России

Выявлены на достоверном уровне и различия в справедливом решении как итоге истории в сказках (социально - культурных традициях) Китая (СКТ Китая) и России (СКТ России) с применением Х2 Р. Пирсона $\left(\chi^{2}=5,9, p=0,015\right)$. На рисунке 2 видно, что третье лицо предлагает справедливое решение в Китайских сказках чаще.

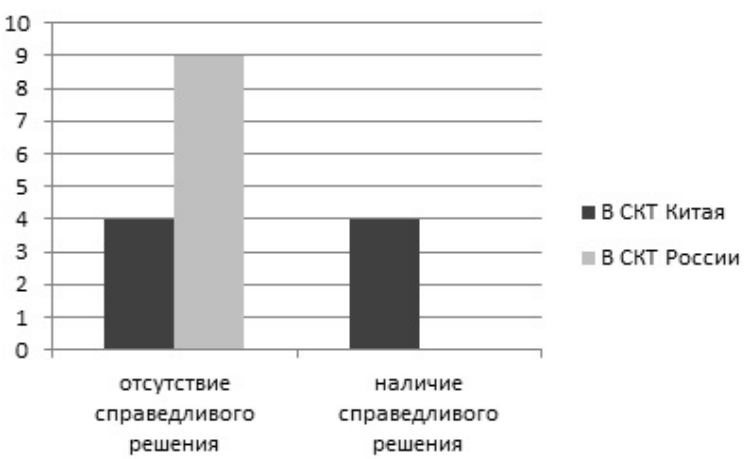

Рисунок 2. Наличие справедливого решения уполномоченными посредниками в текстах Китая и России

Силовые способы представлены более в разрешении конфрликтов третьими лицами в русских сказках. Выявлены на достоверном уровне и различия в силовых способах третьих лиц в сказках (социально - культурных традициях) Китая (СКТ Китая) и России (СКТ России) с применением Х2 Р. Пирсона ( $\left.\mathrm{X}^{2}=8,2, \mathrm{p}=0,004\right)$. Частота встречаемости представлена на рисунке 3. 


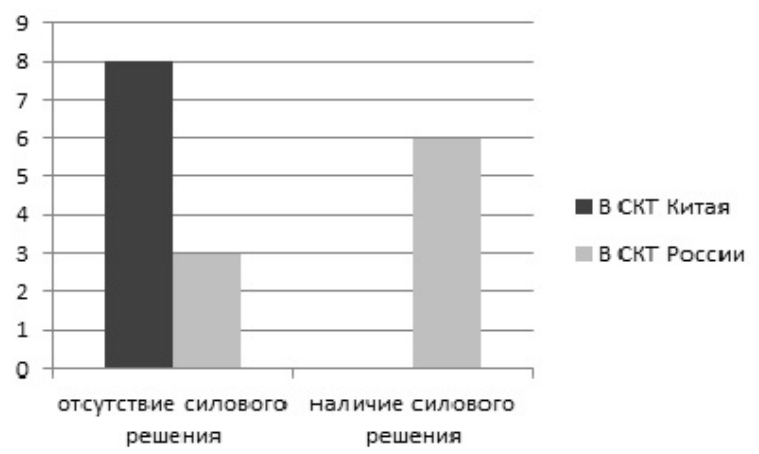

Рисунок 3. Наличие и отсутствие силового разрешения конфликта третьими лицами в текстах Китая и России.

Различия, выявленные в ходе нарративно - дискурсивного анализа и качественно - количественного контент анализа в разрешении конфликтов третьими лицами, может быть объяснено тем, что провокация специально организуется в дискурсе китайского мифа для принятия справедливого решения в ходе конфликта.

Это доказывает коэфрфициент Крамера 0,77 ( $V=0,77, \mathrm{p}=0,028)$, взаимосвязь между показателями «провокацией в конфрликте» и «справедливым решением». В русской мифологии провокация используется для достижения своих интересов третьей стороной, на что указывает Крамера равный 0,66 ( $V=0,66, p=0,047)$ между показателями «провокацией в конфликте» и «направленность на свои интересы».

Таким образом, наблюдается различный подход в управлении конфликтом в социальных представлениях в форме мифов и сказок в культурах России и Китая. Особенностью разрешения конфрликтов, в китайской культуре является разрешения конфликта силовыми методами в меньшей степени, чем в культуре России. В культуре Китая для разрешения конфликтных ситуаций стороны чаще прибегают к помощи третьей стороны, которая в свою очередь заслуживает доверия сторон конфликта. Несомненно, таким же образом необходим анализ и в других культурах для формирования более полного образа способов и методов управления конфоликтными ситуациями.

\section{Литература}

1. Анцупов, А.Я., Шипилов, А.И. Конфликтология - М.: Юнити, 2000. - 551с.

2. Брунер, Дж. Жизнь как нарратив // Постнеклассическая психология, 2005 Том 1. - №2. - С. 9-29.

3. Кутковая Е.С. Нарратив в исследовании идентичности/ Национальный психологический журнал. - 2014. - № 4. - С. 23 -33. 
4. ЛеБарон М. Медиация и культура // Медиация и право .-2012.— № 4.- С. 40-43.

5. Леонов Н. И. Конфрликтология: Учеб.пособие / Н. И. Леонов. - 2-е изд., испр. $и$ доп. - М.: Издательство Московского психолого-социального института; Воронеж: Издательство НПО «МОДЭК», 2006.

6. Макадамс Д.П. Психология жизненных историй // Язык, коммуникация и социальная среда. - 2014.- № 12.- С. 9 -49.

7. Мельникова О.Т., Хорошилов Д.А. Предмет качественного исследования как методологическая проблема социальной психологии // Национальный психологический журнал №1(9)/2013, 50-61

8. Сарбин Т.Р. Нарратив как базовая метафора для психологии. // Постнеклассическая психология, 2004. - №1. - с.6-28.

9. Barresi J., Juckes T.J. Personology and the narrative interpretation of lives // J. Person.

10. 199765 P. 693-719.

\section{RESOLUTION AND MANAGEMENT OF CONFLICTS IN THE CULTURES OF RUSSIA AND CHINA}

N. I. Leonov, Glavatskikh V. G., Glavatskikh M. M. (Udmurt state University, Izhevsk, Russia)

The growing tension in the modern world obliges modern psychology to find ways to manage conflicts in such a way that the conflict itself is a controlled process, the outcome of which should be constructive, leading to the removal of contradictions and tensions in society. The article reveals the specifics of conflict management and the degree of influence of third parties in the conflict in the cultures of Russia and China. The roles of third parties in conflict management in different cultures are defined. The article considers culture as a system forming the consciousness of the individual, manifested in myths and legends of peoples.

Keywords: the Image of the conflict situation, ideas about the conflict, the method of conflict resolution. 